Chapter 6.6

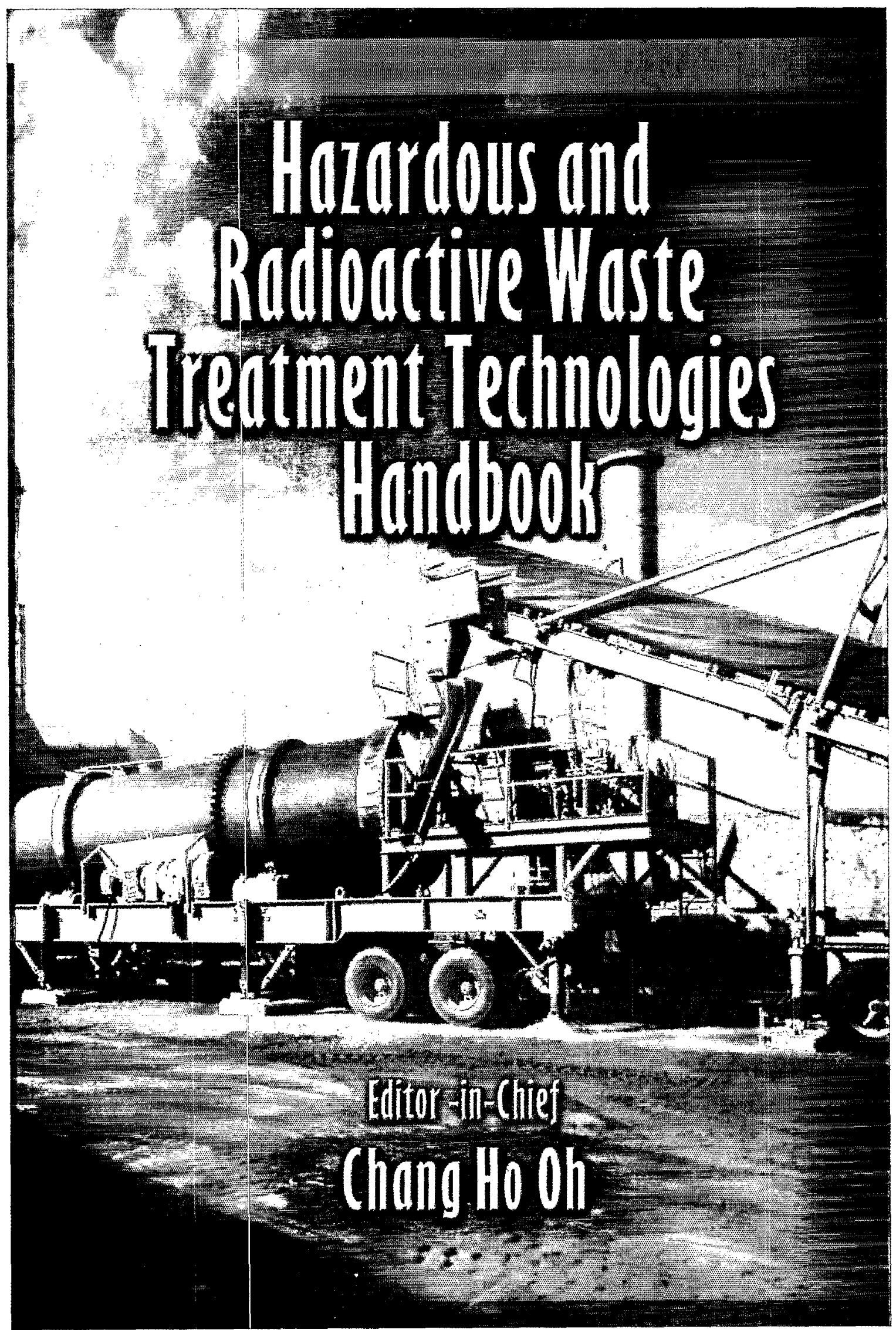

*This work was performed under the auspices of the U.S. Department of Energy. 


\title{
Sulfur Polymer Encapsulation
}

\author{
Paul D. Kalb \\ Brookhaven National Laboratory \\ Upton, New York
}

\section{Introduction}

Sulfur polymer cement (SPC) is a thermoplastic polymer consisting of $95 \mathrm{wt} \%$ elemental sulfur and $5 \mathrm{wt} \%$ organic modifiers to enhance long-term durability. SPC was originally developed by the U.S. Bureau of Mines as an alternative to hydraulic cement for construction applications. Previous attempts to use elemental sulfur as a construction material in the chemical industry failed due to premature degradation. These failures were caused by the internal stresses that result from changes in crystalline structure upon cooling of the material. By reacting elemental sulfur with organic polymers, the Bureau of Mines developed a product that successfully suppresses the solid phase transition and significantly improves the stability of the product. SPC, originally named modified sulfur cement, is produced from readily available, inexpensive waste sulfur derived from desulfurization of both flue gases and petroleum. The commercial production of SPC is licensed in the United States by Martin Resources (Odessa, Texas) and is marketed under the tradename Chement 2000 . It is sold in granular form and is relatively inexpensive ( $\$ 0.10$ to $0.12 / \mathrm{b}$ ).

Application of SPC for the treatment of radioactive, hazardous, and mixed wastes was initially developed and patented by Brookhaven National Laboratory (BNL) in the mid-1980s (Kalb and Colombo, 1985; Colombo et al., 1997). The process was subsequently investigated by the Commission of the European Communities (Van Dalen and Rijpkema, 1989), Idaho National Engineering Laboratory (Darnell, 1991), and Oak Ridge National Laboratory (Mattus and Mattus, 1994). SPC has been used primarily in microencapsulation applications but can also be used for macroencapsulation of waste. SPC microencapsulation has been demonstrated to be an effective treatment for a wide variety of wastes, including incinerator hearth and fly ash; aqueous concentrates such as sulfates, borates, and chlorides; blowdown solutions; soils; and sludges. It is not recommended for treatment of wastes containing high concentrations of nitrates because of potentially dangerous reactions between sulfur, nitrate, and trace quantities of organics. Recently, the process has been adapted for the treatment of liquid elemental mercury and mercury contaminated soil and debris.

SPC is similar to polyethylene in that they are both thermoplastic binders; but because the melt viscosity is significantly lower ( 25 centipoise), it can be easily processed using a simple, heated, stirred mixing vessel. The melt temperature of $S P C$ is $119^{\circ} \mathrm{C}$ and the acceptable process temperature range is 130 to $150^{\circ} \mathrm{C}$. Unlike conventional hydraulic cement formulations, SPC final waste forms do not typically result in an increase in volume because the molten SPC can fill interstitial void spaces in the waste. SPC combined with an aggregate filler (such as waste) tends to develop relatively high compressive strength, typically 13.8 to 34.5 $\mathrm{MPa}$ (2000 to $5000 \mathrm{psi})$. SPC waste forms are comparatively brittle and fail by a shattering fracture when subjected to an axial compressive load. Thermal cycling and exposure to radiation doses of up to $10^{8} \mathrm{rad}$ have little measurable impact on mechanical integrity. Similar to hydraulic cement, expansion of some waste materials on becoming rehydrated through exposure to saturated conditions can cause swelling and/or cracking of the waste form, depending on the type and quantity of waste encapsulated. However, BNL has 
shown that addition of a small percentage of fiberglass fibers supplements the tensile strength of the binder and greatly improves resistance to swelling and cracking under these conditions (Colombo et al., 1997). Testing for microbial degradation using current test method protocols (ASTM G-21 and ASTM-G22, 1970), has not resulted in any negative impacts. However, these methods are not designed to examine the effects of specific thiobacillus microbes, which can potentially attack sulfur. Relatively long-term durability for SPC has been observed by examining sewer pipes fabricated from SPC concrete after numerous years in service and finding no significant deterioration.

\section{Sulfur Polymer Stabilization/Solidification}

Mercury is a particularly hazardous element because it is highly toxic and has a very high vapor pressure. In addition, it is a difficult constituent to treat effectively, especially if commingled with radioactive contaminants (i.e., mixed waste). Conventional techniques for treating elemental mercury, commonly referred to as amalgamation, reduce the leachability of the toxic mercury, but result in a highly dispersible powder and do not effectively immobilize the radioactive contaminants. A new technique developed at BNL (patent pending) known as Sulfur Polymer Stabilization/Solidification (SPSS) was specifically developed for the treatment of liquid elemental mercury and mercury-contaminated soil and debris. SPSS treatment is conducted in two stages. SPC binder and proprietary additives are first reacted with the waste to chemically stabilize the mercury. Then the mixture is heated, melted, and cooled, forming a solid final waste form in which the stabilized waste is physically encapsulated. Mercuric sulfide formed by the stabilization reaction has a low solubility under normal and low $\mathrm{pH}$ conditions (hence leaches at a low rate) and a much lower vapor pressure than elemental mercury (greatly reducing volatilization). Tests have shown that the process effectively captures $99.7 \%$ of the mercury in the stabilized waste form while very little of the mercury $(0.3 \%)$ is volatilized during processing where it is captured in the off-gas system.

\section{Equipment Selection}

\section{Batch Processing Vessels}

Because of its low melting point and low melt viscosity, SPC can be successfully processed by a variety of simple, heated mixing vessels. Bench- and pilot-scale development work was conducted using several types of heated batch mixers, including low- and high-shear blade mixers and double planetary orbital mixers (Kalb and Colombo, 1985). The latter provides a highly efficient mixing pattern at relatively low mixing speeds, thereby diminishing air and gas entrainment within the molten mixture. Heating can be provided by thermocouple-controlled electric resistance band heaters, steam generators, or hot oil circulation heaters (Kalb et al., 1991; Kalb et al., 1999). A pilot-scale cone mixer (Ross Mixers, Happaugue, New York) equipped with a helical auger that rotates on its own axis and around the circumference of the vessel, is shown schematically in Figure 6.6.1. This vessel was used to demonstrate the SPSS process and treat several drums of mercury contaminated soil and more than $90 \mathrm{~kg}$ of liquid elemental mercury. The system is heated by a circulating hot oil system and volatiles are condensed by a chiller. Figure 6.6 .2 is a photograph of the integrated pilot-scale processing system.

Other processing techniques have also been examined. Two types of production-scale mixers - the Holo-Flite mixer (Denver Equipment Co.) and Porcupine Processor - have been evaluated by Idaho National Engineering and Environmental Laboratory (Darnell, 1993). Each uses hot oil media to heat the vessel and the hollow mixing shafts. The Holo-Flite, depicted in Figure 6.6.3, has dual shafts with auger-type flights and is discharged by raising the height of the vessel to allow gravity feed through a weir pipe. The Porcupine Processor, shown in Figure 6.6.4, has a single shaft with hollow, flat-shaped paddles that are separated by breaker bars protruding from the vessel walls to provide better scraping and mixing action. GTS Duratek (Oak Ridge, Tennessee) has successfully microencapsulated incinerator fly ash in SPC using a steam-heated, high-shear mixer in batches of approximately $1360 \mathrm{~kg}$ ( $1.5 \mathrm{tons}$ ). Mixers that allow processing under negative pressure are preferred as they reduce the required process temperature and facilitate capture of off-gases. 


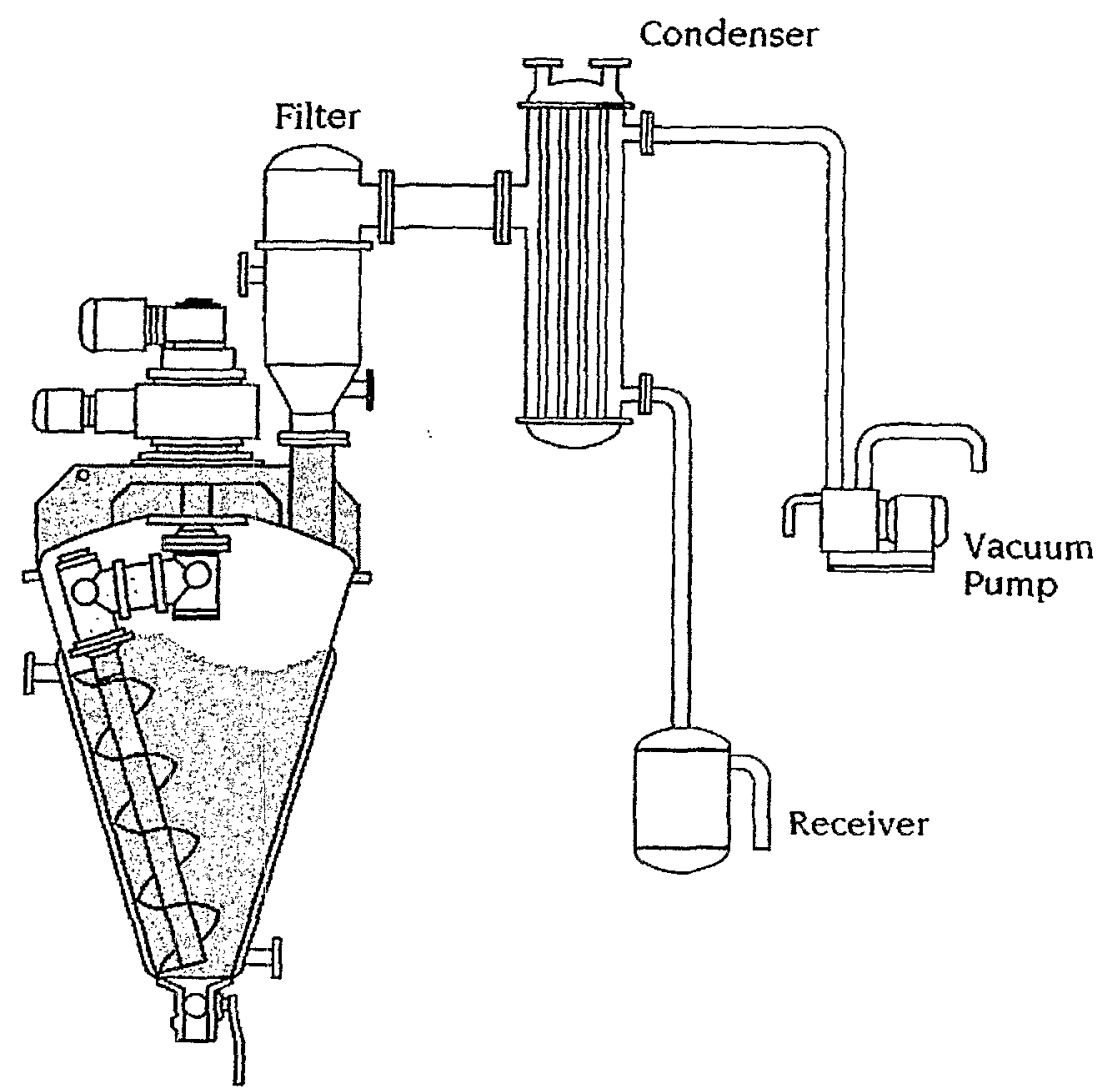

FIGURE 6.6.1 Schematic diagram of a double planetary cone mixer manufactured by Ross Mixer, Inc.

\section{Ancillary Process Equipment}

Unlike polyethylene, SPC microencapsulation is usually conducted in batch mode, in which proper feed ratios of waste and binder are more easily achieved because segregation of materials is not as critical. Volumetric, loss-in-weight, or belt feeders can all be used. Because the process temperature for SPC microencapsulation is 130 to $150^{\circ} \mathrm{C}$, moisture and VOCs may be volatilized during processing, thus requiring installation of an appropriate off-gas collection system. A typical system includes a condenser and/or other means of trapping vapors (e.g., cryogenic trap, impinger), carbon filter to collect VOCs and mercury vapor, and a HEPA filter for radioactive particulates. Figure 6.6.5 is a schematic diagram of the SPSS off-gas collection system used for treatment of mixed waste mercury. Process results at BNL indicated that $99.7 \%$ of the mercury treated remained in the final waste form, $0.3 \%$ was captured in the off-gas treatment train, and no mercury was detected in the gas vented to the environment.

\section{Pretreatment Requirements}

Volatile constituents that are vaporized are not readily trapped in the molten mixture and can be removed in the off-gas system because the relatively low viscosity of the molten SPC mixture does not tend to entrain the vapors. Likewise, batch processing allows sufficient time for vapor removal. Nevertheless, for wastes that contain high concentrations of moisture or other volatiles, it is usually more efficient to pretreat the waste using equipment described elsewhere. Compared with polyethylene, its lower-melt viscosity makes SPC microencapsulation able to tolerate a broader range of particle sizes. Only those particles that exceed the size specifications of the process vessel require pretreatment prior to processing. 


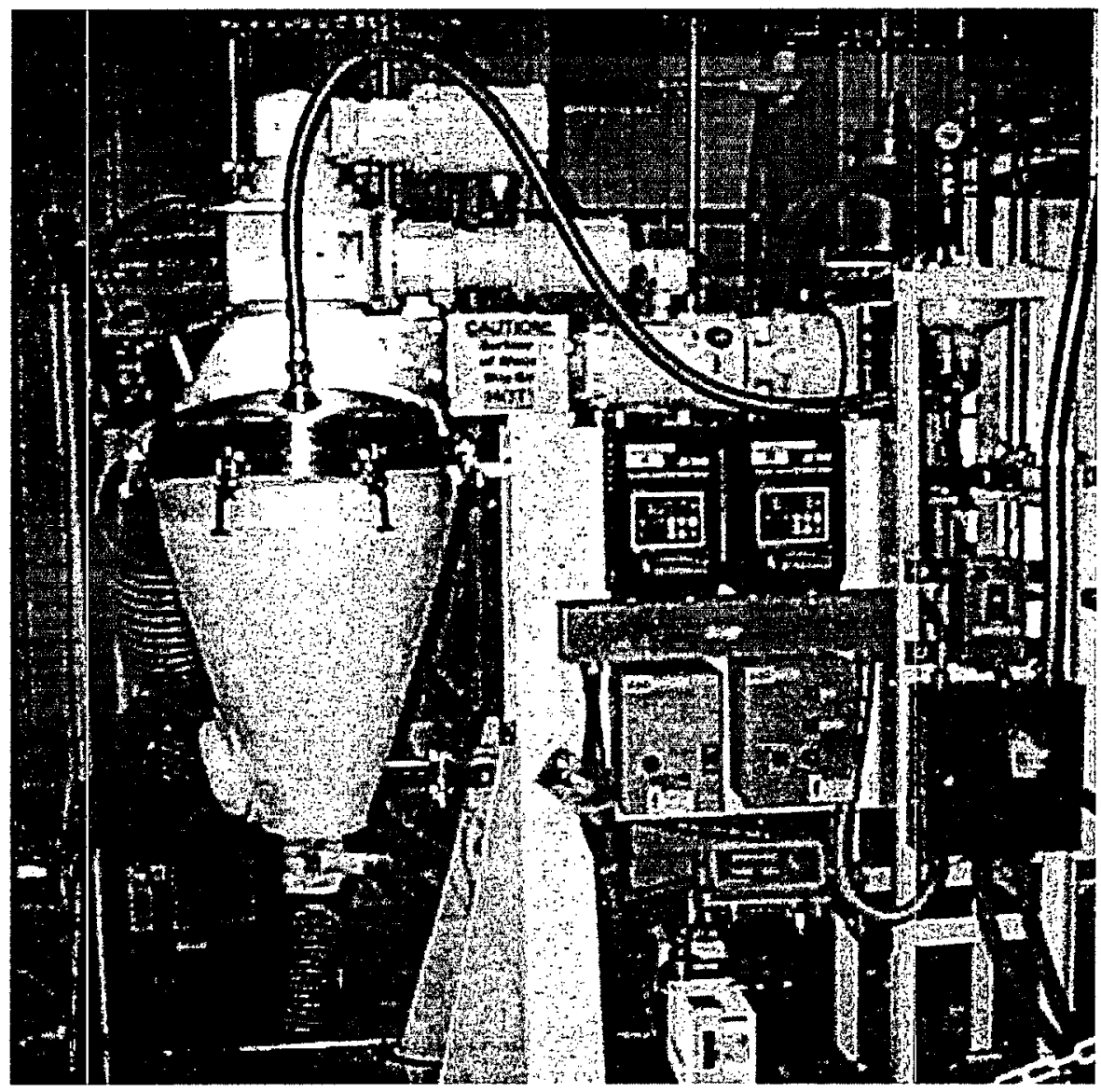

FIGURE 6.6.2 The integrated pilot-scale SPSS process installed at BNL.

\section{Formulation Optimization}

Successful optimization of SPC final waste form composition requires consideration of both processing parameters and final waste form performance. Sufficient workability of the mixture must be ensured to allow homogeneous mixing and operation of equipment within mechanical limits. The range of successful waste loading for SPC microencapsulation varies, depending on the physical properties of the waste stream and the concentration of the contaminants of concern. Typically, waste loadings for SPC microencapsulated waste forms range from 40 to $70 \mathrm{wt} \%$, depending on the chemical and physical properties of the waste. This compares with typical waste loadings of 10 to $30 \mathrm{wt} \%$ for hydraulic cement waste forms.

If maximurn waste loadings are exceeded, the molten mixture can become excessively dry and thick, preventing adequate distribution of the materials. In extreme cases, excessive load on the equipment can cause mechanical failures in mixing blades, shafts, motors, and gears. Operating mixing equipment with overly dry, abrasive mixtures can also create premature wear on vessel surfaces. Successful workability and processing do not guarantee that the final waste form product will meet the desired performance criteria. If waste loadings exceed the point at which the SPC binder can effectively microencapsulate individual waste particles, the ability of the waste form to immobilize contaminants will be diminished. 


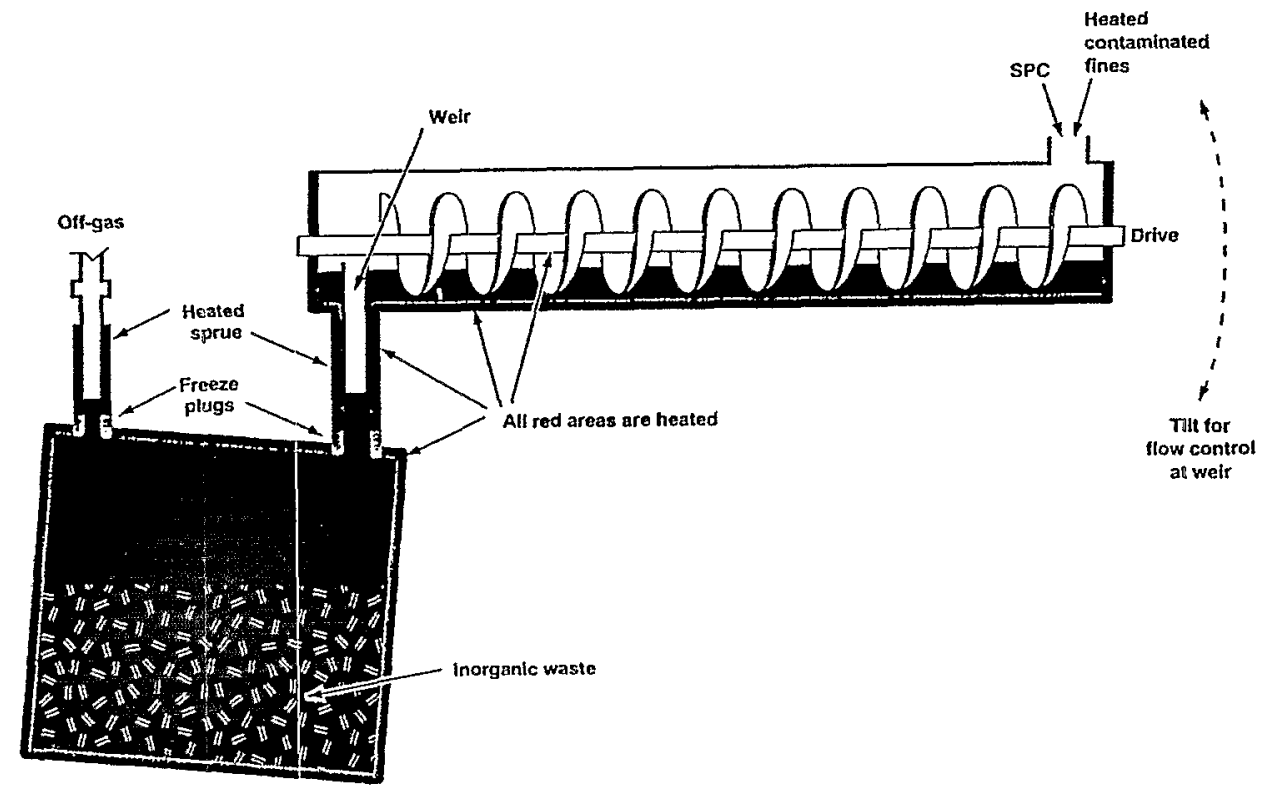

FIGURE 6.6.3 Holo-Flite mixer. ings for physical pdraulic

d thick, tipment tipment ccessful desired ectively ninants

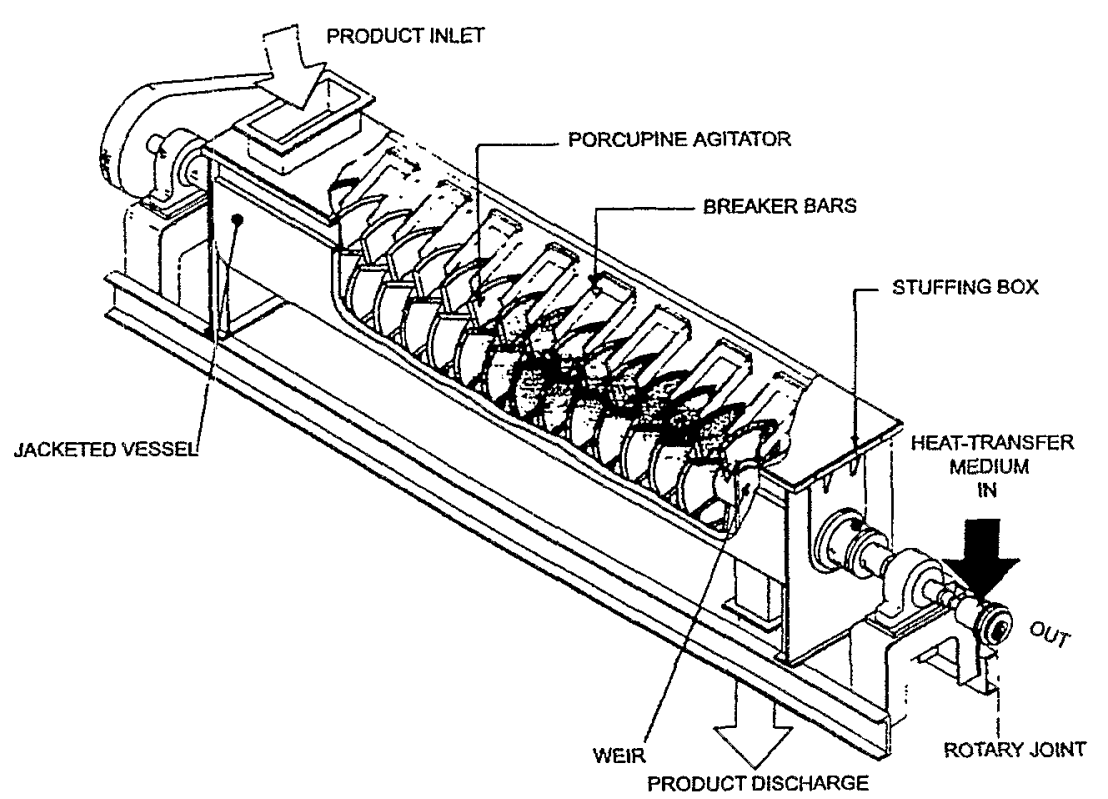

FIGURE 6.6.4 Porcupine processor.

\section{Final Waste Form Performance}

As discussed previously, SPC waste forms are relatively durable and have been demonstrated to meet minimum durability criteria established by the NRC for low-level radioactive waste forms (e.g., compressive strength, thermal, microbial, and radiation stability). 


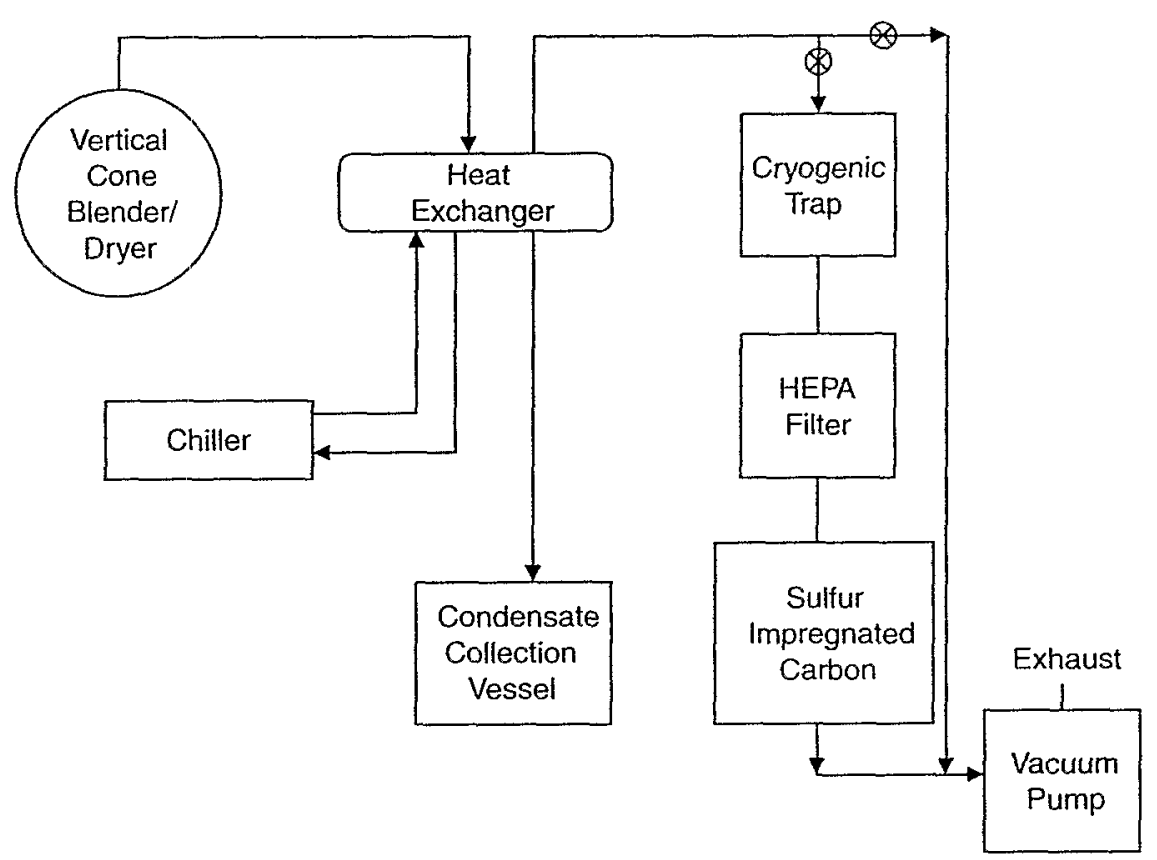

FIGURE 6.6.5 Schematic diagram of the SPSS off-gas collection system.

\section{Leachability}

As with other microencapsulation technologies, leachability of wastes treated by SPC microencapsulation varies as a function of the waste characteristics (e.g., solubility), waste loading, and contaminant concentration. Leachability for SPC waste forms is typically four to eight orders of magnitude better than the minimum requirements established by the NRC. Leach index data for SPC waste forms is shown in Table 6.6.1 and ranges from 9.7 to 14.6 .

TABLE 6.6.1 Leach Indices for Sulfur Polymer Microencapsulated Waste Forms

\begin{tabular}{lcrrr}
\hline & & \multicolumn{2}{c}{ Leach Index } \\
\cline { 3 - 5 } Waste Type & $\begin{array}{c}\text { Waste Loading } \\
\text { (wt\%) }\end{array}$ & ${ }^{{ }^{10} \mathrm{Co}}$ & ${ }^{137} \mathrm{Cs}$ \\
\hline $\mathrm{Na}_{2} \mathrm{SO}_{4}$ & 25 & 12.5 & 10.6 \\
\multirow{2}{*}{ Incinerator ash } & 40 & 10.7 & 9.7 \\
& 20 & 14.0 & 11.2 \\
& 40 & 14.6 & 11.1 \\
\hline
\end{tabular}

Because the SPSS process combines both chemical stabilization and microencapsulation, leachability is reduced even lower. Long-term leachability of mercury was measured from SPSS final waste forms by means of the Accelerated Leach Test (ASTM C-1308). Similar to ANS 16.1, this method is a dynamic leach test in which the leachant is replaced on a periodic basis. Data is evaluated using a related computer program that calculates incremental and cumulative contaminant fractions released, identifies predominant leaching mechanisms and effective diffusion coefficients, and enables prediction of long-term leachability if diffusion is the controlling mechanism. Leach data closely matched that predicted by the diffusion model, thus indicating that diffusion predominates. Following 11 days of leaching, a total of only $5.8 \times 10^{-4}$ percent of the mercury leached from the waste form. The effective diffusion coefficient was measured to be $4.15 \times 10^{-18}$. 
Leachability of toxic metals from SPC microencapsulated waste forms is generally low and can be enhanced by the use of stabilization additives. Toxicity Characteristic Leaching Procedure (TCLP) data for incinerator ash containing extremely high concentrations of lead and cadmium before and following SPC microencapsulation is presented in Table 6.6.2. Leachability of these metals can be further reduced by optimization of the stabilization additive formulation and/or by means of the chemical stabilization step employed in SPSS. Leachability of toxic mercury from SPSS waste forms, given in Table 6.6.3, is well below current TCLP concentration limits for both of the drums treated. In addition, leach results were well below the more stringent Universal Treatment Standard criteria when the formulation was optimized by adding $0.5 \%$ additive.

TAB:LE 6.6.2 Toxicity Characteristic Leaching Procedure (TCLP) Data for Incinerator Fly Ash Treated by SPC Microencapsulation

TABLE 6.6.3 Toxicity Characteristic Leaching Procedure (TCLP) Data for Mixed Waste Mercury Contaminated Soils Treated by SPSS

\begin{tabular}{lcc}
\hline \multicolumn{1}{c}{ Formulation } & $\begin{array}{c}\text { TCLP Conc. Hg, } \\
(\mu \mathrm{g} / \mathrm{L})\end{array}$ & $\begin{array}{c}\text { Total Hg, } \\
(\mu \mathrm{g} / \mathrm{L})\end{array}$ \\
\hline Untreated soil, Drum E & 208 & 4190 \\
60 wt\% Drum E soil, 40 wt\% SPSS & 147 & $\mathrm{NM}^{3}$ \\
Untreated soil, Drum A & 914 & 5570 \\
60 wt\% Drum A soil; 39.5\% SPSS; 0.5\% additive & 0.5 & $\mathrm{NM}^{\mathrm{a}}$ \\
TCLP limit & 200 & $\mathrm{NA}^{\mathrm{b}}$ \\
UTS limit & 25 & $\mathrm{NA}^{\mathrm{b}}$ \\
\hline
\end{tabular}

${ }^{\mathrm{a}} \mathrm{NM}=$ not measured.

${ }^{\mathrm{b}} \mathrm{NA}=$ not applicable.

\section{Summary}

SPC is a low-temperature thermoplastic material that can be used for both microencapsulation and macroencapsulation of wastes. SPC can be produced from abundant waste sulfur, and thus cost of the binder is relatively inexpensive. The low-melt viscosity of SPC allows for easy processing using simple heated mixing equipment. High-waste loading and low leachability have been established for a wide range of radioactive, hazardous, and mixed wastes. SPC has been demonstrated at bench, pilot, and production scales. Sulfur Polymer Stabilization/Solidification is a newly developed process specifically designed to treat mercury and mercury-contaminated soil and debris. The mercury is chemically stabilized to lower vapor pressure and leachability, and the chemically stabilized residual is then physically encapsulated, further lowering leachability and dispersion hazards. SPSS is currently under commercial development. 


\section{Defining Terms}

Microencapsulation: Thorough and homogeneous mixing of small waste particles (i.e., $<60 \mathrm{~mm}$ ) with a liquid binder which then solidifies to form a solid, monolithic final waste form. Individual waste particles are coated and surrounded by the solidified binder to provide mechanical integrity and act as a barrier against leaching of contaminants.

Macroencapsulation: Packaging large pieces of waste (i.e., $>60 \mathrm{~mm}$ ) not suitable for processing by microencapsulation and surrounding the package with a layer of clean binder material. The binder forms a protective layer around the waste that provides structural support, prevents dispersion, and helps reduce migration of contaminants.

Thermoplastic polymers: Polymers with a linear molecular structure that repeatedly melt to a flowable state when heated and then harden to a solid when cooled.

Hydraulic cement: Class of cementitious materials that require addition of water and solidify as a result of various hydration reactions that occur.

Amalgamation: Process by which materials are reacted with various metals such as copper, gold, silver, etc. to form an alloy with different properties. In the case of mercury amalgams, the products have reduced volatility and solubility. Reacting mercury with elemental sulfur also results in products with lowered volatility and solubility and thus is typically referred to as an amalgamation process. Because these reaction products are actually new compounds, however, the reaction is not actually an amalgamation process.

\section{References}

American Society of Testing Materials (ASTM), 1970. Standard Recommended Practice for Determining Resistance of Synthetic Polymeric Materials to Fungi, ASTM G-21. New York, NY.

American Society of Testing Materials, (ASTM) 1970. Tentative Recommended Practice for Determining Resistance of Plastics to Bacteria, ASTM G-22. New York, NY.

Colombo, P., Kalb, P.D., and Heiser, J.H., 1997. Process for the Encapsulation and Stabilization of Radioactive, Hazardous, and Mixed Wastes, U.S. Patent No. 5,678,234.

Darnell, G.R., 1991. Sulfur Polymer Cement, A new stabilization agent for mixed and low-level radioactive waste, in Proceedings of the the First International Symposium on Mixed Waste, A.A., Moghissi and G.A. Benda, Eds., Baltimore, MD.

Darnell, G.R., 1993. Non-radioactive full-scale tests with sulfur polymer cement for stabilization of incinerator ash, in Proceedings of the Fifteenth Annual U.S. Department of Energy Low-Level Radioactive Waste Management Conference.

Kalb, P.D., Adams, J.W., Milian, L.W., Penny, G., Brower, J., and Lockwood A., 1999. Mercury bakeoff: technology comparison for the treatment of mixed waste mercury contaminated soils at BNL, in Proceedings of Waste Management '99, Tucson, AZ.

Kalb, P.D. and Colombo, P., 1985. Modified sulfur cement solidification of low-level wastes, BNL-51923. Brookhaven National Laboratory, Upton, NY.

Kalb, P.D., Heiser, J.H., and Colombo, P., 1991. Modified sulfur cement encapsulation of mixed waste contaminated incinerator fly ash, Waste Manage. J., 11:14-153.

Mattus, C.J. and Mattus, A.J., 1994. Evaluation of Sulfur Polymer Cement as a Waste Form for the Immobilization of Low-Level Radioactive or Mixed Waste, ORNL/TM-12657. Oak Ridge National Laboratory, Oak Ridge, TN.

Van Dalen, A. and Rijpkema, J.E., 1989. Modified Sulphur Cement: A Low Porosity Encapsulation Material for Low, Medium, and Alpha Waste. Nuclear Science and Technology, EUR12303. Commission of the European Communities, Brussels. 


\section{For Further Information}

The references cited in Section 6.6 provide additional useful information on sulfur polymer microencapsulation as well as other alternative $S / S$ technologies. 